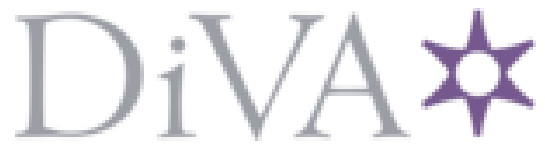

http://www.diva-portal.org

Preprint

This is the submitted version of a paper published in Journal of manufacturing systems.

Citation for the original published paper (version of record):

Holm, M. (2018)

The future shop-floor operators, demands, requirements and interpretations

Journal of manufacturing systems, 47: 35-42

https://doi.org/10.1016/j.jmsy.2018.03.004

Access to the published version may require subscription.

N.B. When citing this work, cite the original published paper.

Permanent link to this version:

http://urn.kb.se/resolve?urn=urn:nbn:se:his:diva-14975 


\title{
The future shop-floor operators, demands, requirements and interpretations
}

\author{
Magnus Holm \\ University of Skövde \\ Box 408, 54128 Skövde, Sweden \\ magnus.holm@his.se
}

\begin{abstract}
The evolution of production industries reveals continuous progress and development throughout the years. This evolution not only includes production methodologies and the production equipment, it also includes the working environment of the shop-floor operators. The demands faced by the shop-floor operators have developed from strictly controlled, simple and monotonic tasks to self-controlled team work requiring a holistic approach that aims at continuous improvements and achieving a high degree of flexibility, adaptability and initiative.

This paper describes the evolution of the shop-floor operator, according to the research literature and interviews with production managers and HR specialists. In addition, the paper presents the response of future Swedish shop-floor operators, today's high-school students, to a description of their possible future work as shop-floor operators. The Swedish production industry competes, to a large extent, on and responds to the international market. The findings made in this paper are thus also interesting for other industries and countries acting on the international market.
\end{abstract}

Keywords: Future shop-floor operator;

\section{Introduction}

In recent times, Sweden has had a positive national trade surplus [1]. The competition in the international marketplace is constantly increasing and, as an export-dependent country, it is vital that the nation's manufacturing industries are competitive and adaptive, in order for them to maintain a leading position. The challenges faced by production companies not only include variables of productivity, but also an increased level of knowledge among staff that enables them to fully utilise the production systems. Future production challenges are anticipated to emphasise the importance of developing the knowledge, abilities and scope of the employees, not only in the engineering departments, but also on the shop-floor. Good collaboration within shop-floor teams that have both novice and highly experienced operators is vital, when complexity and the demands of adaptability in future production systems increase and time-to-market decreases. An increasing pace together with more advanced machines and complex production systems lead to a more information intensive working environment. It raises demands of technical support systems to help the shop-floor operators handle, prioritise and act on available and incoming information, in order to maintain a high production output.

The production industry in Sweden has identified the need for extended technical knowledge and competence in handling future production systems, in order to maintain a high level of competitiveness and productivity [24]. Among the key employees are the ones closest to the production systems, the shop-floor operators. To facilitate and enhance a collaborative approach on the shop-floor, supportive tools focusing on the operators are needed [5-9].

\section{Methodology}

In addition to reviewing the published research literature, two related studies were undertaken investigating the future shop-floor. The first study involved interviews with production managers and HR specialists from industry, to obtain their perspective on the future shop-floor operator. The second study involved 
questionnaires with high-school students about their response to the future shop-floor operator proposed by production managers and HR specialists.

The goal was to capture each individual manager's understanding and predictions for the future shop-floor. Since it was not possible to gather all eight managers and specialists for a focus group and, therefore, the method of use selected was Interviews. The interviews with the managers and specialists were made individually at each company. The questions used are listed in Appendix A. In the presentation of the results from the interviews in this paper, the names of the participants and the companies are anonymous, to avoid any possible identification of the sources.

Students attending technical high schools, with relevant backgrounds and a predicted future within industry, were targeted as participants in the second study. Recurrent visits at our University by several technical high school classes provided a representative group, including more than 200 students who could participate in the second study. Questionnaires were chosen as a tool for collecting the inputs from the students. In order to gain control of the process in general and especially regarding the information given to the participants the same standardised information was given to all. The questionnaire used by the students is listed in Appendix B.

\section{Evolution of the industrial shop-floor operator}

Yesterday's shop-floor operators were stationed at one machine or focused on one specific task. In contrast, today's shop-floor operators face an increasing range of tasks, demands and responsibilities. Parallel to this transformation, the difference between blue collar and white collar responsibilities and scope has faded. Many of the engineering duties formerly carried out by white collar workers are today within the responsibilities of the shop-floor teams.

The development of the shop-floor is, of course, a mirror of the changing conditions faced by the production industry in general. Shifting management strategies have obviously affected all employees in one way or another. The concept of Scientific Management presented at the beginning of the last century focused on efficiency. The shop-floor operator was almost considered as a machine along with other machines on the shop-floor. According to Scientific Management, the shop-floor operator was in need of firm supervision and a rigid structure, in order to reach high productivity. The areas of explicit knowledge, decisions and conclusions belonged to the white collar workers who were not expected to emerge from their offices onto the shop-floor [10-12].

In 1948, the concept Method Time Management (MTM) emerged and during the following years it was introduced to industry. Through analyses of manual tasks, focusing on and evaluating possible improvements, MTM enabled improved ways of working. The MTM-concept has had a substantial impact on the development of the manufacturing industries' productivity and competitiveness, also, of course, on the working environment of the shop-floor operators. In the 1980's, the Toyota Production System (TPS), a production and management concept, began its triumphal march over the world, also strongly influencing Swedish industry. Along with yet another management philosophy, Total Quality Management (TQM), the focus was set on the expectations and requests of the customer, as well as the production variables, quality and flexibility. These somewhat new shop-floor foci resulted in an increased motivation to work with continuous improvements and the elimination of waste, not only for the engineers but also including the shop-floor operators. A high level of commitment and a broad range of adaptability are keys to the successful implementation of any management and/or production philosophy, not least on the shop-floor. The production philosophies emerging from TPS, TQM and Lean have strongly influenced most of the world's production companies on both management and shop-floor levels, and still do so today [8, 13-22].

Having a pro-active approach on the shop-floor is an important strategy that facilitates greater flexibility and a possible reduction of the total lead time at assembly stations. Such approaches can counteract possible uncertainty caused by stochastic events (errors, breakdowns, etc.) during production [5, 23]. One of the strengths of a human operator is the ability to adapt to different situations, make a decision and act upon it. However, in a dynamically changing workshop environment with stochastic events that negatively affect the production system, shop-floor operators neither possess all the available information nor do they have the capability to process or evaluate it in real time. To make good decisions, the operators need a system that supports decision-making, communication and collaborative work, as well as facilitates a learning process enhancing a proactive shop-floor [6, 14, 24, 25]. Views of and demands on the shop-floor operators of today, provided during the interviews and from the research literature, are described in Figure 1. 


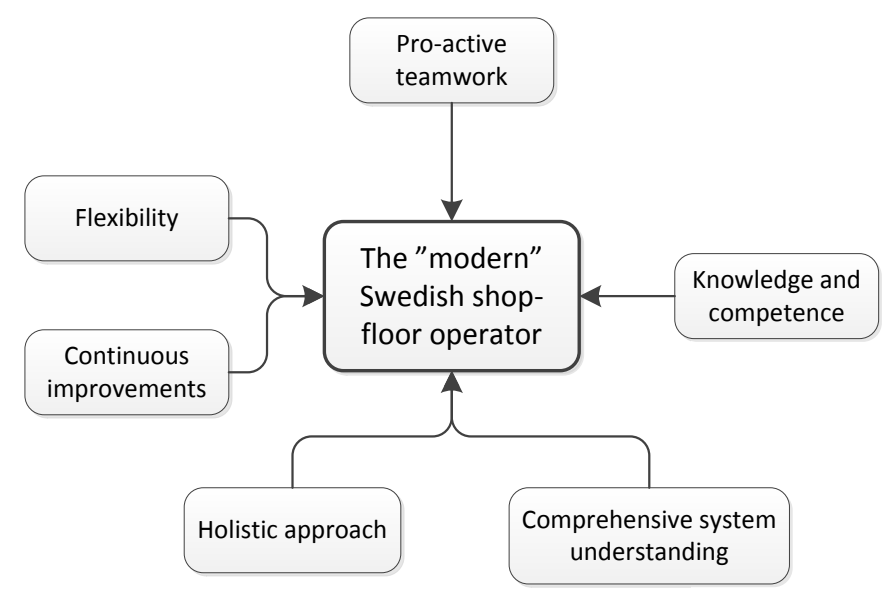

Figure 1. Demands on today's shop-floor operator according to interviews and literature.

As indicated in the research literature, the evolution of industry has not had the shop-floor operators in focus. Research has concentrated on management, methodologies and the production systems. Though the role and importance of the shop-floor operators are eventually going to change.

\section{Managers' views of the future Swedish shop-floor operator}

To further investigate the scope and demands of the future shop-floor, interviews were conducted with eight production managers and HR specialists at six Swedish production companies. These six manufacturers range from a local company with 60 employees to an international production company whose local factory site has more than 1000 employees. These companies, process and cut metal and wood, in sectors such as automotive, industrial automation and supply of the construction industry. Their shop-floor operators are engaged in machining as well as assembly operations.

The managers, who have been engaged in research collaboration with the University of Skövde for several years, have given their views of the present and the future Swedish shop-floor operators and shop-floor working environments. The conclusions of the production managers and HR specialists have been presented to the future and up-coming shop-floor operators, namely, today's high school students. Their response embraces both deviations and consensus.

During the interviews with the production managers and HR specialists, a model describing four quality areas when developing industrial work was used as a basis for the interviews [24]. The four areas are:

- Individual - team

- Skills

- Improvement and development work

- Management and communication.

A team-based approach on the shop-floor and operators within the teams that rotate workplaces are used by all companies engaged in the interviews. The vital importance of social interaction and discussion on the shopfloor was emphasised by all interviewees and they all agreed that a team-based working environment in the future will be the leading approach. However, a probable extended scope requires shop-floor operators with an ability to handle an additional number of complex tasks, in order to maintain high productivity as well as a high level of quality. A trend that was identified in some of the companies was factories within the factory [26]. The team (or teams) responsible for each of these in-house factories had all the responsibility to optimise the production. The teams' responsibilities not only included normal production tasks, such as machining and assembly operations, but also included, e.g., preventive maintenance, continuous improvements, production analyses and failure handling. Nonetheless, the members of the teams will, of course, change over time. Assuring the total competence of the teams was emphasised, to ensure the ability to maintain high productivity and quality.

The predicted increasing scope of responsibility on the shop-floor indicates possible variables limiting the capability of the teams. The shop-floor operators' own interest and experience is regarded by the interviewees as the most important variables facilitating the level of individual responsibility and eventually the teams'. Today, most of the interviewees' companies demand a degree from a technical high school, when employing a shop-floor operator, but knowledge in automation, NC and material science is also sought-after. Although the 
most important individual variable is personality, all of the interviewees agreed that technical knowledge and competence cannot compensate for lack of momentum or individual responsibility.

All of the interviewees agreed, as stated in [24], that each individual's understanding of tasks and acceptance of applied working standards are key variables for making continuous improvements and developing the process along with an engaged individual's own knowledge and ideas. Other vital issues raised during the interviews were the importance of having short decision processes, to ensure that the engagement on the shop-floor is not lost, and the importance of understanding the level of quality required by the customer.

Looking back, one can clearly see that the level and complexity of automation and the number of embedded systems have increased and, looking ahead, the interviewees predict that it will continue to evolve. Beyond technical excellence, which is predicted to become even more important than today, the subsequent attributes are considered by the interviewees as being vital for future shop-floor operators, in addition to the previously mentioned: a thorough technical education, having multi-language skills, being a creative team player, logical and mathematical thinking, dexterity, flexibility, awareness, innovation, momentum and accuracy.

Technical progress enables large volumes of production data and information to be displayed to the shop-floor operator in real-time. However, the information systems of today still look the same as yesterday's systems and are usually not able to sort, prioritise and handle the large volume of information in a smart way. The teenagers of today, who will be the future shop-floor operators, often use smartphones and other powerful ICT-devices as an indispensable part of life, but using these devices on the shop-floor is often a delicate matter today. Smartphones are seen by some of the interviewees as possible tools on the future shop-floor and all of them foresee that the importance of decision support tools will increase.

The intense and demanding shop-floor environment that requires an even broader range of knowledge and technical expertise, together with increasing quantities of information and more speed, predicts a need of shop-floor decision support. In striving to make the shop-floor an even more attractive work-place, it is important to merge different demands. Can IT-devices, such as smartphones, etc., be used as shop-floor tools for a decision support system, e.g., and at the same time enhance the shop-floor's attractiveness?

The human operator is, in general, flexible and can adapt to different situations [14]. However, as predicted by the managers, in an information intensive environment, facing dynamically changing demands and stochastic events that negatively affect production, the shop-floor operator is not able to either process or evaluate all existing information needed to make informed decisions and prioritisations at all times. It is not possible for any shop-floor operator to hold and process all production information in real-time and be a rational decisionmaker (completely informed, infinitely sensitive, rational and know exactly what to do) [27], but a welldesigned decision support system can help. Research has been conducted on industrial decision support and it is expected that industrial interest and funding will increase. Though a change of focus, from managerial, is needed to ensure the relevance of decision support research also for the shop-floor [28-31].

Probable technologies that could be integrated on the future shop-floor are Augmented Reality, as an everyday tool for displaying information, along with Cobots - robots cooperating with human shop-floor operators without fences between them [32]. When discussing Augmented Reality applications, the interviewees drew a timeline reaching year 2020 until practical shop-floor implementation was expected to become a reality. It is expected that an increased level of technology on the shop-floor is essential for making the shop-floor an appealing workplace for young people in the future. The scope of enhanced demands on future shop-floor operators provided during the interviews is depicted in Figure 2. The demands depicted in Figure 2 are all not completely new (e.g. not present on todays' shopfloor) but are predicted having enhanced importance by the interviewees. 


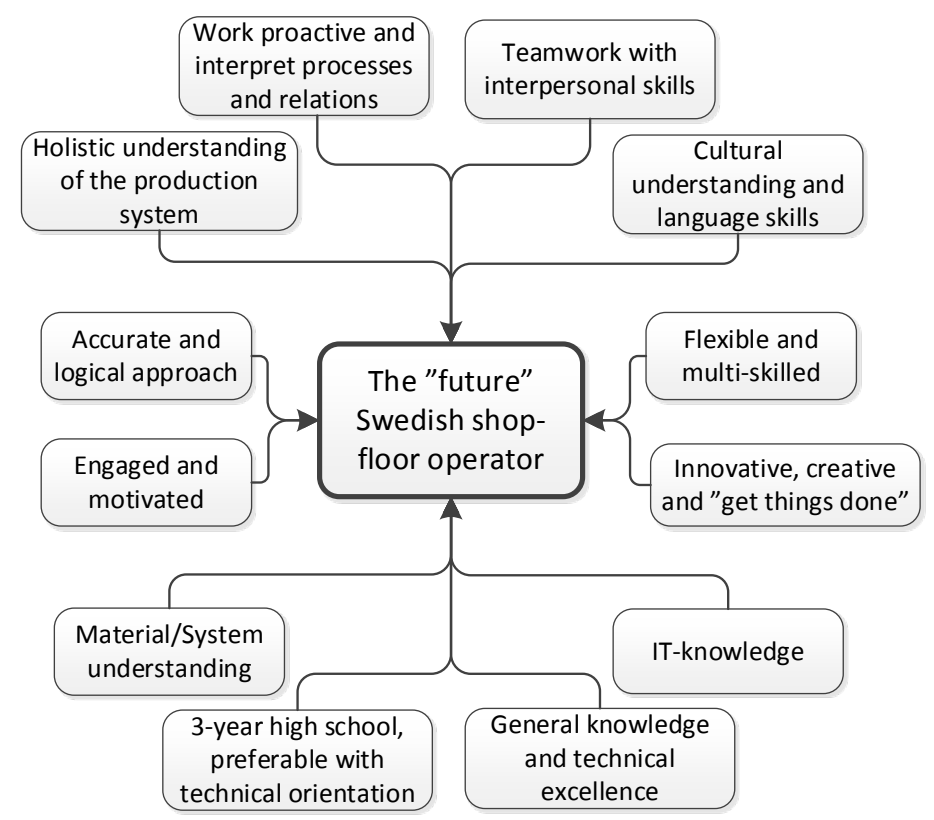

Figure 2. Enhanced demands to meet for the future shop-floor operators.

\section{Responses to the managers' views of the future shop-floor operators}

The number of demands and skills that employers require of future shop-floor operators, as predicted by the production managers and HR specialists, will drastically increase, compared to the situation faced by today's shop-floor operators (Figure 1). A majority of the defined abilities can be considered as non-technical or personal characteristics (modelled to the left, above and to the right in Figure 2). Only a limited number are referred to as the individuals' technical knowledge and abilities, along with requested level of education (modelled in the lower part of Figure 2). The managers' and specialists' expectations of the abilities and knowledge of their future employees were presented to their probable future employees and colleagues: 237 Swedish high-school students, 17-18 years old, attending $2^{\text {nd }}$ or $3^{\text {rd }}$ year of three-year technical programs. The high school students came from eight classes at four different high schools from Skövde and nearby cities (high school in Sweden is the educational level before University). The classes visited the University of Skövde on an annual research event focusing technical high-school students.

During seminars the high-school students were given information about ongoing research focusing the future shop-floor and the predictions made about the future shop-floor during the interviews with production and HRmanagers. They were then asked to respond to a questionnaire about their contacts with production industries, their view of shop-floor work and their response to the managers' predictions.

Of all the high-school students, almost $70 \%$ had attended field trips to production companies and an approximately $45 \%$ had worked at a production company themselves. Only $6 \%$ stated they had no previous contact with any production company (Figure 3). The answers to the questionnaire from the high-school students without previous contact with the production industry did not diverge from the answers by the students with personal experience of the production industry and are consequently not presented separately. The high-school students answering the questionnaire are further on referred to as the respondents. 


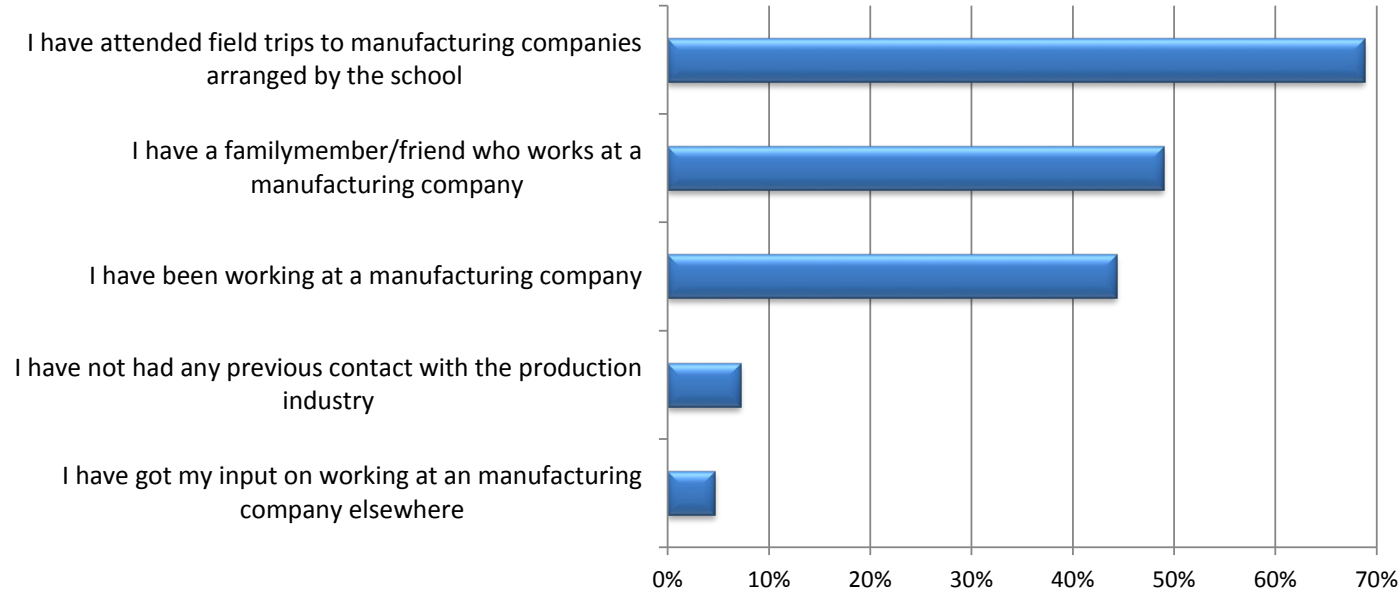

Figure 3. The 237 respondents' previous contacts with the production industry (more than one input per respondent were allowed).

The 237 respondents were given 30 words/short statements and asked to select the 3-5 they thought most applied to their view of the work of a shop-floor operator at a Swedish production company today. The selected top three were development, teamwork and accuracy, followed by other positive opinions, such as good salary and good working environment. Their view of shop-floor work is predominantly positive. An alignment of the respondents' answers and the given words/statements is shown in Figure 4.

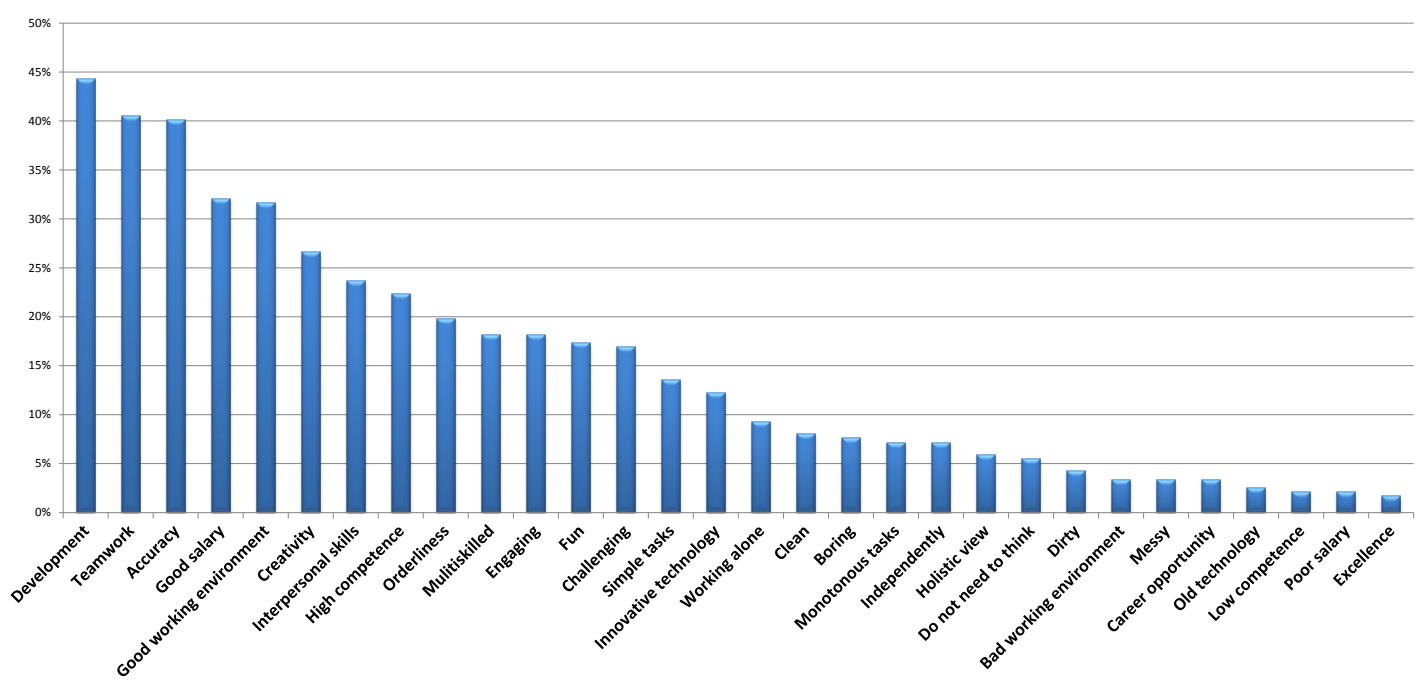

Figure 4. The 237 respondents' views of the work of a shop-floor operator (3-5 inputs per respondent). 
So what are the respondents' interpretations of the managers' demands of the future shop-floor operators, as presented in the interviews? Six of the predicted future demands (depicted in Figure 2) were presented to the respondents:

- To be a team player with interpersonal skills

- Innovative, creative and get thigs done

- Holistic understanding of the production system

- Flexible and multi-skilled

- IT-knowledge

- Work proactively and an ability to interpret processes and relationships

When analysing the interviews made these were the demands having a somewhat fuzzy definition made by the interviewees. To further analyse the understanding of the demands each respondent was given a pair of the demands and asked to provide their own interpretations, given the context that they were shop-floor operators working at a production line with both manual and automatic assembly stations. Their answers for each statement were categorised into groups (see Sections 5.1 - 5.6).

\subsection{To be a team player with interpersonal skills}

Already today teamwork is a reality on most shop-floors. The managers predict this will continue and that more responsibilities will be demanded from the shop-floor teams in the future. A uniform view emerges from the respondents' answers to the question "What does it mean to be a team player with interpersonal skills?" Of a total of 68 answers as many as 66 considered it to be an ability to cooperate, interact and support each other.

\subsection{Innovative, creative and "get things done"}

The importance of having a well-functioning knowledge triangle, combining education, research and innovation [33], and an ability to keep and further develop a leading position, is indicated by Swedish industry [2, 3]. All of the interviewees agreed that the workers entering the shop-floor as operators in the future must have at least a degree from a technical high school to be able to interact with the intense technical environment and be part of further development. The shop-floor operators are expected use and further develop innovations emerging from research. How did the respondents answer the question "What does it mean to be innovative, creative and get things done"?

The answers could be divided into three groups. Two of the groups were of equal size embracing $80 \%$ of the 81 answers. One of the major groups interpreted the question as "new ways of working, new solutions and a positive attitude", while the other group understood it as "broad knowledge, development of both company and individual". The remaining $20 \%$ of the answers ranged from "I do not know" to "Continuous improvements" to "More automation" and irrelevant answers.

\subsection{Holistic understanding of the production system}

The complexity of the shop-floor is expected to increase, according to the managers, along with increasing production demands resulting in multifaceted scenarios requiring abilities to interpret situations and processes. This demands a holistic view of the shop-floor and its processes. The respondents' answers to the question "What does it mean to have a holistic understanding of the production system?" could be divided into three levels of expected detailed knowledge or understanding (Figure 5). The answers referring to it as "Understand the process" accounted for $38 \%$ while $29 \%$ stated that it is understood as having a "Detailed and deeper knowledge". The answers from $11 \%$ were categorised as "To know every detail". However, as many as $22 \%$ of the 79 answers could not be categorised into any of these three groups, with answers like "I do not know" or irrelevant responses such as "Working with robots." 


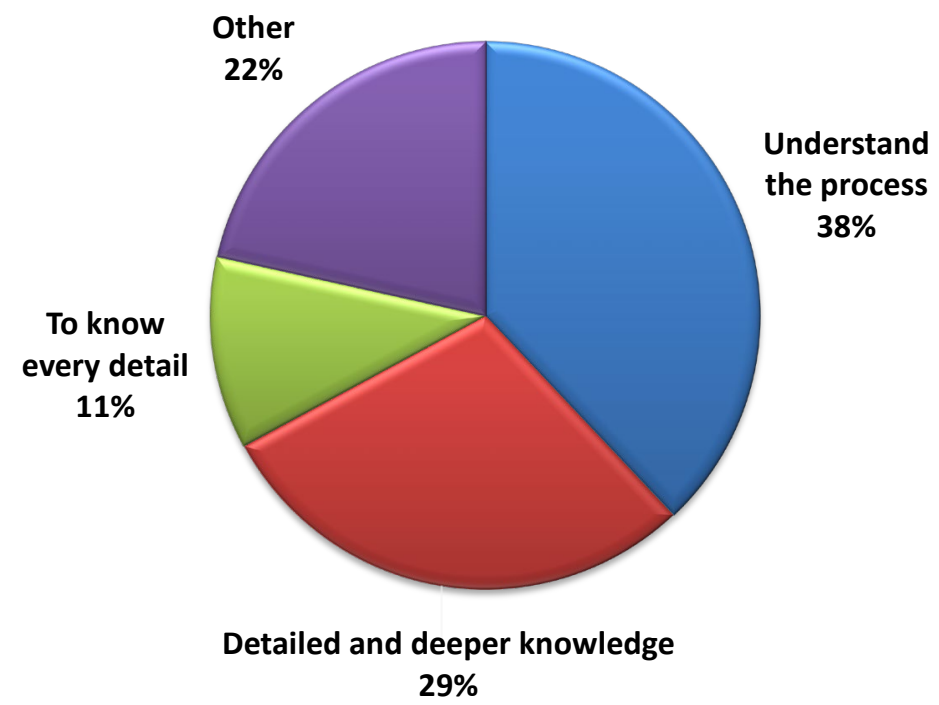

Figure 5. Interpretation of "Holistic understanding of the production system".

\subsection{Flexible and multi-skilled}

As discussed in the research literature, flexibility is already today important, when evaluating the competitiveness of the production industry. The interviewees predict that its importance will further increase in the future. The ability to handle events that occur and the ever-changing demands affecting production systems require shop-floor flexibility and the skills to handle complex machines and processes. The answers to the question "What does it mean to be flexible and multi-skilled?" could be divided into three groups or levels of ability (Figure 6). In total, 70 students answered this question and $60 \%$ considered it to be to know a lot and an ability to work with a lot of things. The next group, $24 \%$, broadened the scope and their answers could be regarded as an extended proficiency and ability to solve problems. Two students (3\%) took it even further. They stated that flexible and multi-skilled could be seen as abilities beyond expectations and scope. Those not knowing or giving an irrelevant answer comprised $13 \%$ of the respondents.

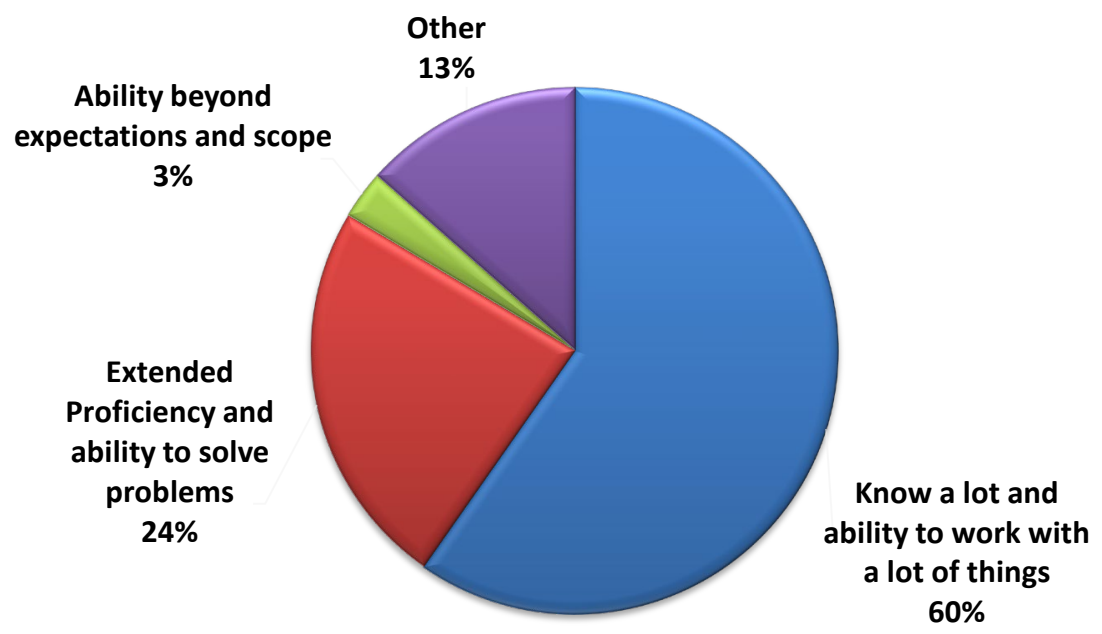

Figure 6. Interpretation of "Flexible and multi-skilled".

\subsection{IT-knowledge}

Young people of today that acknowledge ICT as an inseparable part of life will eventually presume it to be a part of their working hours in the future. During the interviews, the managers and specialists predicted that ITknowledge will be vital for future shop-floor operators and that emerging technologies, like Augmented Reality, 
will be used on the shop-floor of the future. But what is knowledge of IT to the respondents? The 71 answers to the question "What does it mean to have IT-knowledge?" emerged into three levels of IT-abilities (Figure 7). A basic level of IT-knowledge was referred to by $46 \%$ of the respondents as having a "General knowledge of computers and a basic ability to use them". Another $21 \%$ of the answers extended the IT-knowledge to cover "Knowledge about and ability to use the IT-systems in use in production". The third level of IT-knowledge covering $10 \%$ of the answers claimed "Knowledge about and ability to program computers and robots in use in production". However, as many as $23 \%$ answered "I do not know" or gave irrelevant responses to the question.

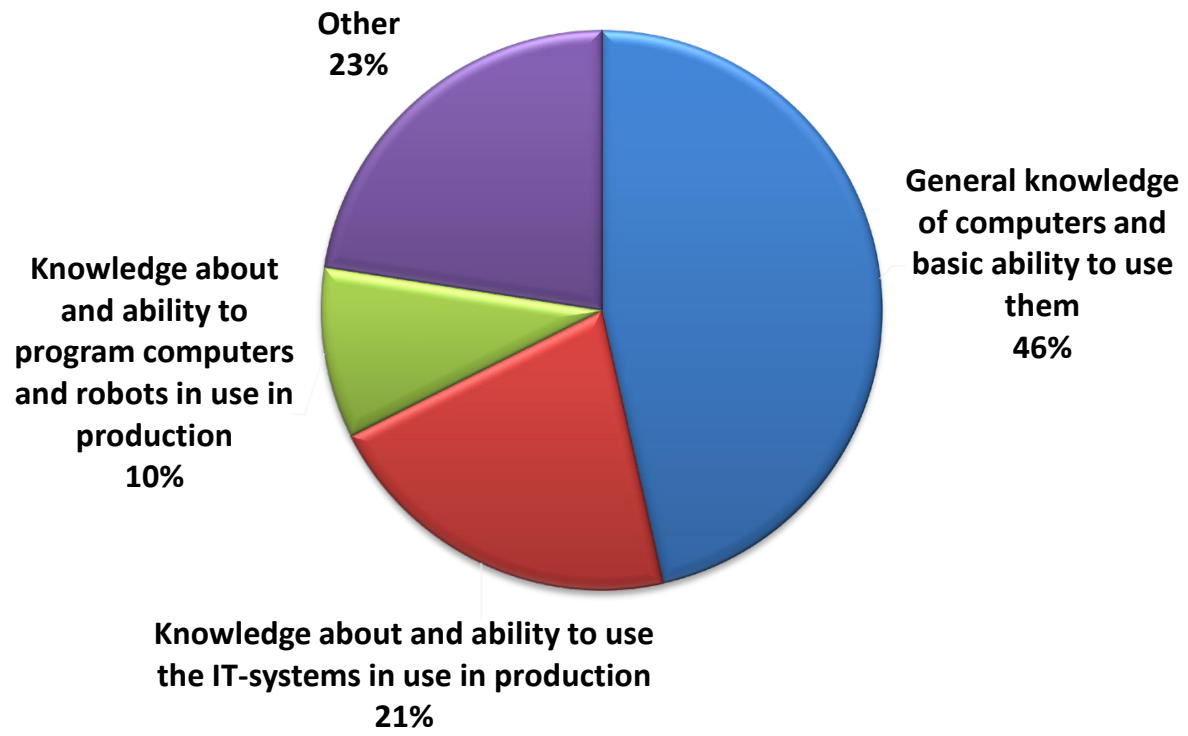

Figure 7. Interpretation of "IT-knowledge".

One answer from a high-school student, who interpreted the meaning of having IT-knowledge, highlighted a gap in the expectation between everyday life and industry:

"IT-knowledge is as important during your work as in everyday life, though industry is possibly a little bit behind".

For industry, it is important not to appear to be overtaken by the IT-evolution. It is important that the impression is the opposite: That industry offers an environment with front-edge technology attracting the possible future employees.

\subsection{Work proactively and an ability to interpret processes and relationships}

Recurring events that negatively affect the production output demand a shop-floor with proactive ways of working and a broad understanding of the production processes, to prevent losses. A proactive approach, which is seen as a common attribute among experienced shop-floor operators, facilitates competitiveness, flexibility and extended functionality of the production systems [23]. The answers to the last of the six questions "What does it mean to work proactively and have an ability to interpret processes and relationships?" are depicted in Figure 8 (in total, 70 answers). Of the answers $31 \%$ could be referred to as "Understand how it works and see connections" and $21 \%$ as "Good at solving problems and see connections". To "Have a broad knowledge and know what to do" concluded the answers from $19 \%$ and $3 \%$ considered it as "Working towards the future". This was the question with the largest group of answers, $26 \%$, that referred to the group of "I do not know" and irrelevant responses. No clear common understanding emerged from the answers. This was the question where the respondents' answers clearly comprised the largest and, in some cases, incompatible scope. 


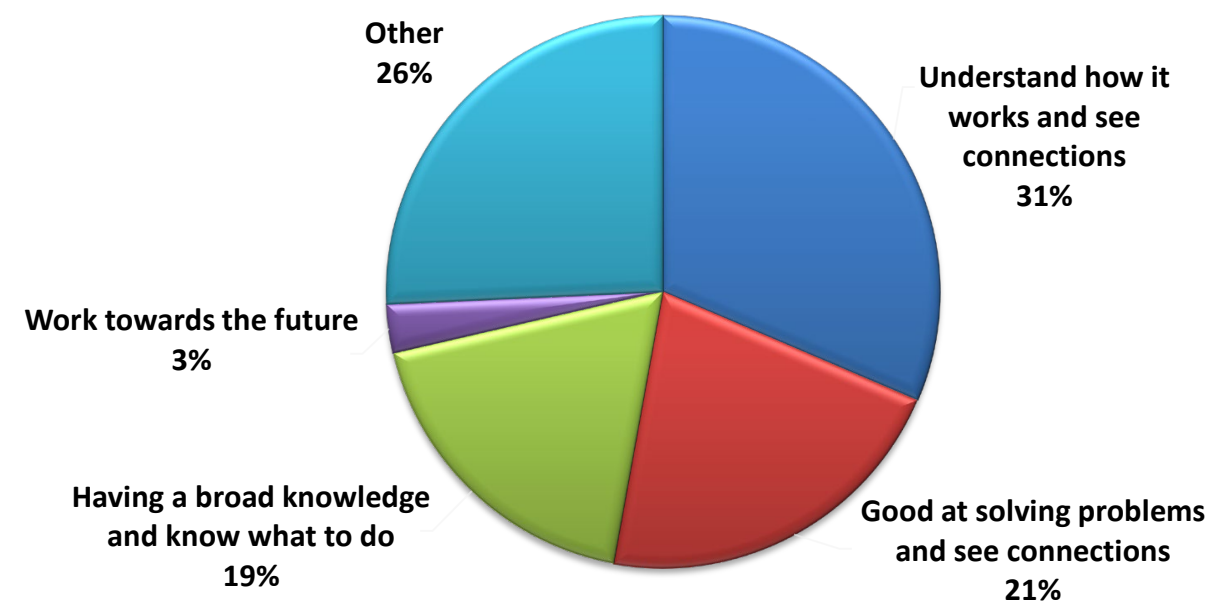

Figure 8. Interpretation of "Proactive work" and of "Processes and relations".

\subsection{The respondents understanding and expectations of the future shop- floor}

During the interviews, a versatile view of the future shop-floor operator including ample demands, especially concerning the personal abilities, was given by the managers and specialists. For some of these views and demands, the respondents gave uniform interpretations, but for most of the views and demands the respondents' interpretations encompass a widely defined scope that includes a large number of irrelevant answers, indicating that there was no common understanding of the questions posed in the questionnaire. The managers and specialists interviewed predicted that the future employment processes for finding and keeping shop-floor staff will be demanding and challenging. This indicates the importance of continuous interaction between school and industry to counteract negative and inaccurate images which will negatively affect the students' future approach towards employment in industry.

The respondents were asked to formulate what they thought to be the most important issues if they were to work as a shop-floor operator in five years from now. Their top three priorities were "A good working environment" followed by "Work mates" and in third place "A good salary" (Figure 9). When their views of shop-floor work (Figure 4), together with the expectations of their future workplace (Figure 9), were analysed a uniform opinion emerged. Their top three priorities of workplace conditions can all be found within their top five statements of shop-floor work. 


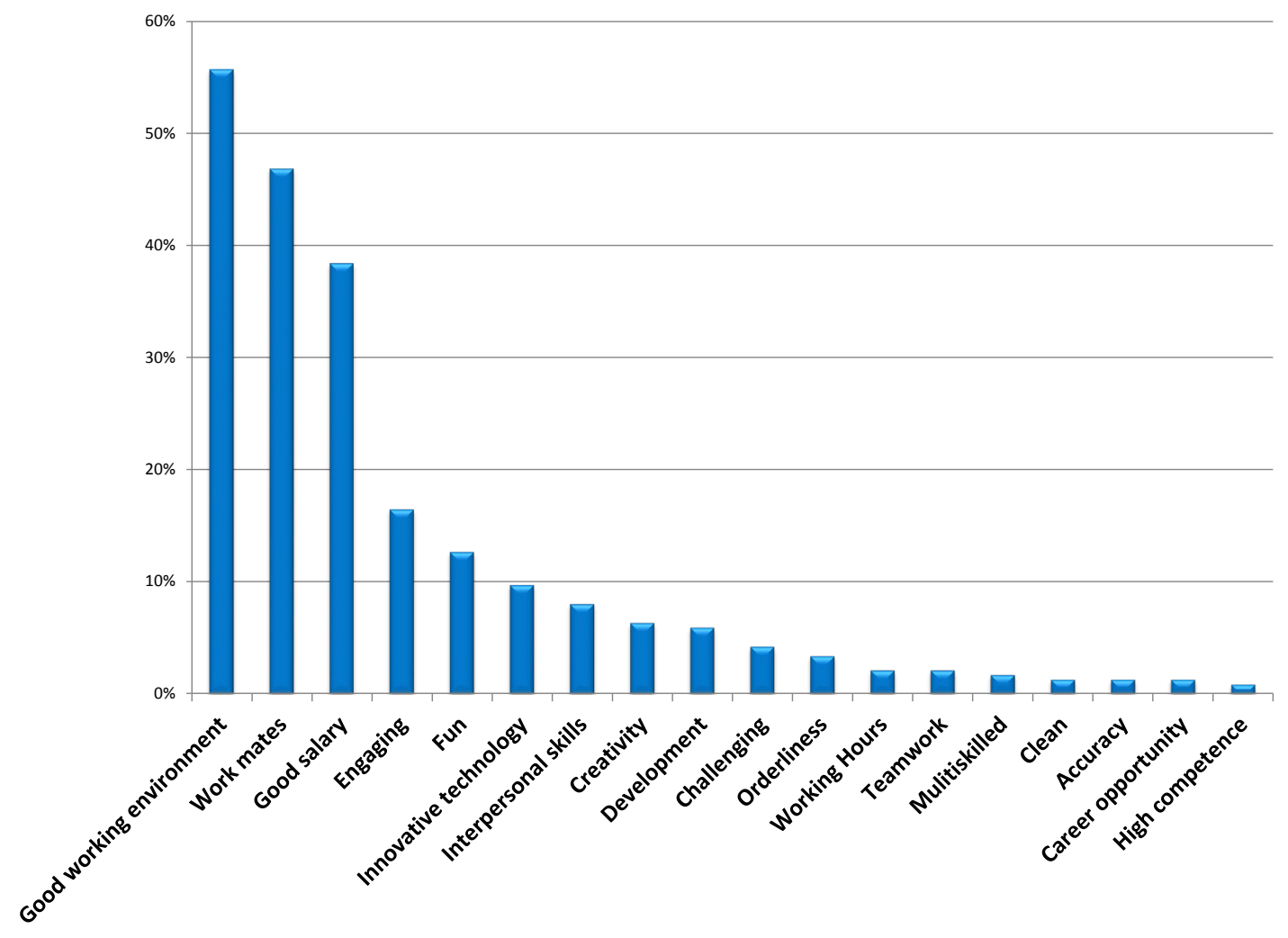

Figure 9. The prioritised conditions for a future working environment according to the 237 respondents (more than one answer per respondent were allowed).

\section{Conclusions and key results}

The scope of the shop-floor operator has, during the last century, evolved from "low knowledge level and single tasks" to "high knowledge level and extensive tasks". Both the research literature and the interviewees provide consistent predictions of a future with even more intensive and demanding shop-floor environments. Such future conditions will need shop-floor operators who are team players with extensive technical abilities and comprehensive interpersonal skills, in order to maintain the high level of productivity that is necessary to succeed on the competitive international market. Since they are vital aspects of the production system, the decisions and actions taken by shop-floor operators directly and strongly affect the productivity.

During the interviews, the limitations of the current shop-floor information systems emerged. To a large extent, the interfaces of the shop-floor information systems look as they did 20-30 years ago, while the rapid development of ICT in general in society has only marginally reached the shop-floor. The use of the computationally powerful smartphones and tablets is usually restricted on today's shop-floors and only used for dedicated production applications in a limited number of companies. Such ICT-devices that are considered as vital parts of many teenagers' lives have the potential to form the basis of a future shop-floor decision support system able to handle and process a vast amount of data and also incorporate emerging technologies such as Augmented Reality.

The demands of the future shop-floor, as described by the interviewees, emphasise the broad scope of abilities and knowledge to be used by the future shop-floor operators. It underlines the need of up-to-date shop-floor support systems but also the necessity that the future shop-floor is developed management and shop-floor operators together, avoiding a dissonance understanding of its presumptions.

The future shop-floor will face tough competition in attracting the highly competent staff required. Although, when analysing the answers from the respondents', it can be concluded that the starting point for shop-floor recruiting is not that dark. As future shop-floor operators, the respondents' view of shop-floor work coincides to a high degree with their own priorities of their future working environment. A future shop-floor decision support system should not only be able to facilitate technical and productivity needs. A well-designed decision support system that supports shop-floor decisions and work could also enhance the attractiveness of working on the shop-floor, by incorporating every-day ICT-devices, such as smartphones and tablets, and in that way support future recruiting. 
The interviewees confirm the research literature, but also extend and confirm the demands that will be faced by future shop-floor operators. However, for many of the investigated requirements, the respondents' interpretations of the future shop-floor demands are irregular. The respondents present uniform interpretations of the two demands "be a team player" and "be innovative, creative and get things done", but the interpretations of the other four demands are less uniform. This indicates that companies must clarify, probably not only to their future staff but also internally, how the demands should be understood, interpreted and implemented.

\section{Acknowledgements}

The author would like to thank the participating managers and specialists and their companies and also the respondents answering the questionnaire.

\section{Funding}

This work was supported by the Swedish Knowledge Foundation and the research project Young Operator 2020 (You2) [grant number 20130303].

Magnus Holm holds a PhD in Manufacturing Engineering from De Montfort University in England. He worked at Siemens Building Technologies and other engineering companies with automation and programming before heading for an academic career in 2004. His primarily research interest are within shop-floor decision support systems.

\section{References}

1. Statistics Sweden. Swedish export and import. 2016 [cited 2017 November 15]; Available from: http://www.sverigeisiffror.scb.se/.

2. Teknikföretagen, Swerea, and S.P. Academy, Svensk Produktion 2025: Strategisk forsknings- och innovationsagenda för att möta de globala utmaningarna. (in Swedish). 2011.

3. Teknikföretagen, et al., Made in Sweden 2030: Strategic Agenda for Innovation in Production. 2013.

4. Kloo, H., et al., Fordonsindustrins kompetensbehov i västra Götaland - En kartläggning (in Swedish), P. Österström and J. Boström Elias, Editors. 2017, Västra Götalandsregionen \& Business region Göteborg.

5. Fasth, Å., et al., Designing proactive assembly systems (ProAct)-Criteria and interaction between automation, information, and competence. Asian International Journal of Science and Technology in production and manufacturing engineering (AIJSTPME), 2010. 2(4): p. 1-13.

6. Grane, C., et al. The operator of the future-a key to competitive industry in a future information society. in Proceedings of the 4th International Swedish Production Symposium. 2012. Linköping

7. Karlsson, M., et al. Could the use of ICT tools be the way to increase competitiveness in Swedish industry? in proceedings of the 12th IFAC/IFIP/IFORS/IEA Symposium on Analysis, Design, and Evaluation of HumanMachine Systems. 2013.

8. Lindberg, P., C.A. Voss, and K.L. Blackmon, International manufacturing strategies: context, content and change. 2013: Springer Science \& Business Media.

9. van Rhijn, G. and T. Bosch, Operator-Oriented Product and Production Process Design for Manufacturing, Maintenance and Upgrading, in Dynamics of Long-Life Assets: From Technology Adaptation to Upgrading the Business Model, S.N. Grösser, A. Reyes-Lecuona, and G. Granholm, Editors. 2017, Springer International Publishing: Cham. p. 133-149.

10. Björkman, T., Den långlivade taylorismen. I Abrahamsson, Abrahamsson, Björkman, Ellström \& Johansson (red) Utbildning, kompetens och arbete (in Swedish). 2002, Lund: Studentlitteratur.

11. Taylor, F.W., Scientific management. 2004: Routledge.

12. Witzel, M., A history of management thought. 2016: Routledge. 
13. Maynard, H.B., G.J. Stegemerten, and J.L. Schwab, Methods-time measurement. 1948.

14. Payne, J.W., J.R. Bettman, and E.J. Johnson, The adaptive decision maker. 1993: Cambridge University Press.

15. Hellsten, U. and B. Klefsjö, TQM as a management system consisting of values, techniques and tools. The TQM magazine, 2000. 12(4): p. 238-244.

16. Nilsson, T., A History of Teams, in Work Teams: Past, Present and Future, M.M. Beyerlein, Editor. 2000, Springer Netherlands: Dordrecht. p. 275-288.

17. Laring, J., et al., MTM-based ergonomic workload analysis. International journal of Industrial ergonomics, 2002. 30(3): p. 135-148.

18. Liker, J.K., The Toyota way: 14 Management Principles from the World's Greatest Manufacturer. 2004.

19. Börnfelt, P.-O., Förändringskompetens på industrigolvet: kontinuerligt förändringsarbete i gränslandet mellan lean production och socioteknisk arbetsorganisation (in Swedish). 2006.

20. Johansson, J. and L. Abrahamsson, The good work-a Swedish trade union vision in the shadow of lean production. Applied Ergonomics, 2009. 40(4): p. 775-780.

21. Johansson, J., L. Abrahamsson, and S. Johansson, If you can't beat them, join them? The Swedish trade union movement and lean production. Journal of Industrial Relations, 2013. 55(3): p. 445-460.

22. Alefari, M., K. Salonitis, and Y. Xu, The role of leadership in implementing lean manufacturing. Procedia CIRP, 2017. 63: p. 756-761.

23. Dencker, K., et al., Proactive Assembly Systems-realizing the potential of human collaboration with automation. Annual Reviews in Control, 2009. 33(2): p. 230-237.

24. Harlin, U., et al., Development of industrial work in the future - a study of Swedish manufacturing companies, in Proceedings of the 4th International Swedish Production Symposium. 2012: Linköping $p$. 414-424.

25. Holm, M., et al., Adaptive decision support for shop-floor operators in automotive industry. Procedia CIRP, 2014. 17: p. 440-445.

26. Skinner, W., The focused factory. Vol. 52. 1974: Harvard Business Review Brighton, MA.

27. Lee, W., Decision theory and human behavior. 1971.

28. Gorry, G.A. and M.S.S. Morton, A framework for management information systems. Vol. 13. 1971: Massachusetts Institute of Technology.

29. Arnott, D. and G. Pervan, A critical analysis of decision support systems research. Journal of information technology, 2005. 20(2): p. 67-87.

30. Arnott, D. and G. Pervan, Eight key issues for the decision support systems discipline. Decision Support Systems, 2008. 44(3): p. 657-672.

31. Arnott, D. and G. Pervan, A critical analysis of decision support systems research revisited: the rise of design science. Journal of Information Technology, 2014. 29(4): p. 269-293.

32. Djuric, A.M., R. Urbanic, and J. Rickli, A Framework for Collaborative Robot (CoBot) Integration in Advanced Manufacturing Systems. SAE International Journal of Materials and Manufacturing, 2016. 9(2016-01-0337): p. 457-464.

33. Allinson, R., K. Izsak, and E. Griniece, Catalysing Innovation in the knowledge triangle. Technopolis Group, Publication for the European Institute of Innovation and Technology, 2012(s 5). 


\section{Appendix A - Questions during interviews}

These are the questions asked during the interviews with the production managers and HR specialists (translated from Swedish).

Background

1. Current position? Duties?

2. How long have you been with the company?

3. Training?

General questions

4. Generally describe your production, various steps?

5. What different roles are there in production? How do they differ?

6. How do you define shop-floor operators in your production?

7. What are the shop-floor operators' main activities / tasks in the production?

8. What skills are required to work as a shop-floor operator in production?

9. How do you organize the shop-floor work? Teams / group / individual / cross-functional teams?

10. What decisions are taken by the operators / team?

11. What information are needed to make these decisions?

12. What technologies / tools (support functions) are used by the shop-floor operators today?

13. What authority does the operators have at fault / downtime for resetting and start-up?

14. How do you engage all shop-floor staff in shop-floor development?

15. What do you do to get a common / holistic approach at the shop-floor?

Vision of the future

16. How has your industry changed during the past 20 years?

17. How do you think it will evolve in the future? $5-10$ years? The shop-floor operators? $10-15$ years?

18. What trends do you predict?

19. If any, what will be the new competences required for future shop-floor operators?

20. What competences do you consider to be crucial for future shop-floor operators?

21. How do you think shop-floor supporting systems / tools will need to develop if the teams' / operators' tasks increases?

22. What plans or visions are there within the company, in terms of technology and organization?

23. What specific techniques do you think will change your production?

24. How does the company develop new supporting systems for the shop-floor operators?

25. How are the shop-floor operators engaged in this development?

26. What is your strategy for recruiting young shop-floor operators in the future?

27. What obstacles do you identify in attracting shop-floor staff in the future?

28. How do you get "older" employees to keep up with shop-floor evolution? How do you motivate them?

Skills development, improvement and development

29. What kind of skills do you predict to be required of the future shop-floor operators?

30. Do you train the shop-floor operators continuously? Long-term / short term?

31. How do you support the shop-floor operators in developing their skills?

32. Has the attitude to learning and development within the company changed over time?

33. What do you consider to be the critical factor for success when developing shop-floor skills?

34. Have the possibilities of learning for the shop-floor operator decreased / increased during recent years?

35. How are shop-floor operators supported in developing their skills?

36. How do you train and develop the necessary "non-technical" skills? (Language, analytical skills, holistic understanding, etc.)

37. What does your approach towards continuous improvements include? How do you engage the shopfloor operators?

Concluding questions

38. Are there anything in particularly interesting you want to highlight?

39. Have you within the company implemented any management concepts / practices? Which? When?

40. Which management trends have affected the company? What about the future? 


\section{Appendix B - Questionnaire for students}

This is the questionnaire used in the second study presented (translated from Swedish).

\section{The future operator}

Future operators, namely those who are employed in our manufacturing industry within 5-10 years, you are today is a teenager. In our research we interviewed production managers and HR specialists who gave their view of the competence requirements of future operators. Now we want your opinion on the manufacturing industry as a workplace and especially the work as an operator.

1. Have you in any way come in contact with a manufacturing company? Select one or more options that apply to you.

$\square$ I have a family member / friend working in the manufacturing industry.

$\square$ I have been on field trips to a manufacturing company.

$\square$ I have worked in a manufacturing company.

$\square$ Other:

$\square$ I have not been in contact with a manufacturing company at all.

2. Have you been able to get a picture of how it is to work at a manufacturing company?

$\square$ I have a family member / friend working in the manufacturing industry.

$\square$ I have been on field trips to a manufacturing company.

$\square$ I have worked in a manufacturing company.

$\square$ Other:

$\square$ I have no idea of how it is to work at a manufacturing company at all.

3. What high school programs are you attending?

$\square$ Technology Program

$\square$ Volvo High School

$\square$ Industrial Technical

$\square$ Other:

4. What words do you fit in to a job as an operator at a Swedish manufacturing company today? Select 3-5 words / statements that you think fit.

Accuracy; Bad working environment; Boring; Career opportunity; Challenging; Clean; Creativity; Development; Dirty; Do not need to think; Engaging; Excellence; Fun;

Good salary; Good working environment; High competence; Holistic view; Independently; Innovative technology; Interpersonal skills; Low competence; Messy; Monotonous tasks; Multi-skilled; Old technology; Orderliness; Poor salary; Simple tasks; Teamwork; Working alone

$\square$ I have no view at all, whether positive or negative, about the work that the operator (no additional options need to be marked).

During the interviews yielded production managers and HR specialists their view of the competence requirements they think will be the future operators. Their words have been compiled in this picture. It's like you can see quite comprehensive competence requirements they see ahead. We would like to have your opinion on these means.

Put yourself in the situation that you are working as an operator on a production line where there is quite a variety of manual assembly stations and some automated assembly stations with robots. 


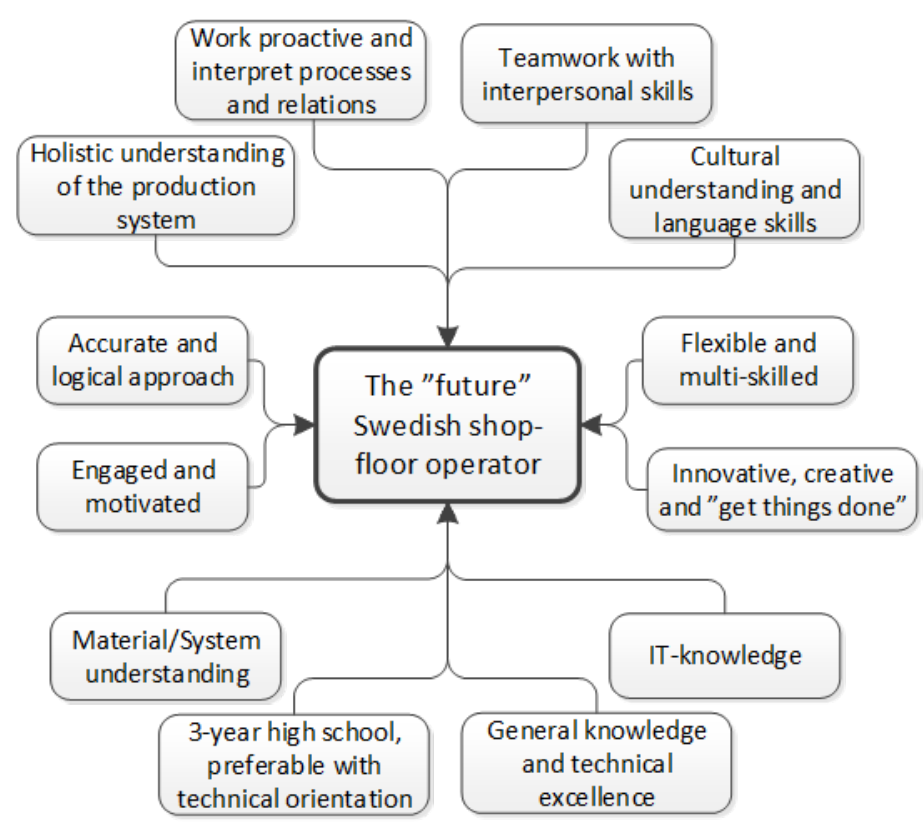

What does it mean to be a team player with interpersonal skills?

What does it mean to be innovative, creative and get things done?

What does it mean to have a holistic understanding of the production system?

What does it mean to be flexible and multi-skilled?

What does it mean to have IT-knowledge?

What does it mean to work proactively and have an ability to interpret processes and relationships?

If in five years you would be working as an operator in the manufacturing industry, what do you think would be the three most important conditions for you to be happy and do a good job? 